Review

\title{
Proper Management of Planetary Hydrocarbon Resources
}

\author{
Florian Ion Tiberiu Petrescu \\ IFToMM, ARoTMM, Bucharest Polytechnic University, Bucharest, Romania
}

Article history

Received: 27-03-2020

Revised: 24-04-2020

Accepted: 23-05-2020

Email: fitpetrescu@gmail.com

\begin{abstract}
Much has been said about the planet's gas and oil resources and many assumptions and speculations have been made regarding their rapid depletion, but a report on the normal and judicious management of these important planetary resources for both energy and other various materials that are obtained today from them, such as composites, synthetic fibers for fabrics, plastics, rubber produced synthetically ... The paper wants to clearly establish how these important planetary resources are produced and obtained, but also the possibility of extension their lives in symbiosis with the greening of the planet through the rational exploitation and use of these resources. Even if new oil and gas deposits are found from time to time, this fact cannot justify the almost continuous operation at large capacities of many of the old processed reserves, which have long been declared on extinct. Something is going on with these old oil deposits. They are in a continually rebuild or bring other deposits from somewhere in the depths of the earth from a probably a huge and deep reserve. The universe we live in is designed in such a way that it abounds in hydrogen, carbon, or combined gases, i.e., hydrocarbons, which under certain conditions pass into a viscous liquid state thus producing oil in large quantities. It is ridiculous to much longer support the theory that gases inside the earth were formed like oil otherwise from organic matter decomposed over time, possibly from dead dinosaurs that rotted and then turned into oil and gas. Hydrogen, the element whose nuclear fusion gives life to stars, including the Sun, is an extremely important wheel in the gear of the Universe and is also the most widespread element in the Universe, being the simplest of all chemical elements. As long as a reserve (bag) of oil or gas is not emptied very quickly, but is rationally exploited, it will recover normally by feeding from the internal source of the planet.
\end{abstract}

Keywords: Matter, Structure, Social Sciences, Hydrocarbons Management, Gas and Oil Rational Exploitation and use, Oil, Gas, Hydrocarbons Energy

\section{Introduction}

Energy today plays a vital role in people's lives, being extremely important and besides nuclear (Petrescu, 2012a-c; 2014; 2018; 2019; Petrescu and Petrescu, 2018; 2019; Petrescu et al., 2017a-d) and green renewable energy one must still consider the massive energy obtained from oil and natural gas.

Oil or crude oil, together with coal and natural gas are part of the deposits of biogenic origin found in the earth's crust. Oil, which is a mixture of solid and gaseous hydrocarbons dissolved in a mixture of liquid hydrocarbons, is a mixture of lipophilic substances. Crude oil (unrefined) contains more than 17000 complex organic substances, which is why it is the most important raw material for the chemical industry (paints, medicines, plastics, etc.) and the production of fuels. As a curiosity, it can be mentioned that some varieties of crude oil become phosphorescent in the presence of ultraviolet light.

Oil was discovered several thousand years ago. With lower density than saltwater, caves and areas with sedimentary limestone, clay, or sandy sedimentary layers have been found (in Germany, for example, around Hanover and Braunschweig). If the impervious clay layers are above, not allowing the oil to the surface, it will be found in the deep layers where it will be extracted by oil wells.

The layers of oil located on the surface by oxidation turn into asphalt, which has already been discovered in the Orient about ca. 12,000 years in ancient Mesopotamia. 
People have learned to use asphalt, by mixing with sand and other materials that seal the ship's walls.

From Babylonia comes the name of naptu (nabatu = illuminates) which indicates that the oil was used for lighting, this being also mentioned in the laws of Hammurabi 1875 BC. being the first written historical evidence for regulating oil use.

Petroleum is a word of Roman origin that comes from "oleum petrae" = stone oil name that the Romans took from the Egyptians, who discovered surface oil in the region of the Suez Gulf mountains. at the axes of the Roman chariots, or during Byzantium this was part of the Greek fire, a weapon feared in the naval battles of old.

Oil was also used in ancient medicine as a universal miracle cure.

Tițeiul has been known on the territory of Romania since the first century BC since the objects discovered in the Dacian fortress from Poiana (Nicorești, Galați): Ornaments of teal reinforced and covered with a thin layer of silver (Bălan and Mihăilescu, 1985). In fact, the first oil refinery in the world was built in Romania, in 1856, (Eakins, 2002) on the outskirts of Ploiești, (in the south-east, on the way to the town of Râfov, to the north of the Ploiești - Buzău railway), by Marin Mehedinteeanu, the lessee of extensive oil deposits on Păcureți estate, Prahova. The refinery installations were quite primitive, all the machines being made of cylindrical vessels of iron or cast iron, heated directly with wood fire. These machines were ordered in Germany from the Moltrecht company that built boilers for the production of oil from bituminous shale and in December 1856 the construction of the "gas plant" in Ploiești, on behalf of Marin Mehedinteanu (who died in 1861), begins. Marin Mehedinteanu's oil distillery, built on an area of 4 ha and having a working capacity of 2710 tonnes per year, (on average 7.5 tonnes/day), started its activity when Teodor Mehedinteanu encountered difficulties in applying of the contract signed since 1856 for the lighting of the capital with "hydrocarbon and lamps" (Boncu, 1971).

The price of oil falls rapidly as the number of refineries increases, lamp oil becomes an increasingly important resource in lighting, gradually replacing candles.

Massive oil exploitation begins in the 19th century due to the widespread use of oil in lighting, which gave better light-producing less smoke compared to whale oil lamps, or wax candles.

In 1852, Canadian physician and geologist Abraham Gesner obtained a patent for refining clean lamp oil called petroleum and in 1855 the American chemist Benjamin Silliman proposed the purification of petroleum with sulfuric acid.

For massive oil production, an intensive drilling period follows. The most famous drill is conducted by Edwin L. Drake on August 27, 1859, in Oil Creek, Pennsylvania and was financed by the American industrialist George $\mathrm{H}$. Bissell, here at $21.2 \mathrm{~m}$ deep oil fields.

After the introduction of electric lighting, the importance of oil in lighting decreased, but the use of fuel in the automotive industry expanded. Rockefeller's family of American industrialists, the founders of Standard Oil Company, convinced the public to use gasoline instead of ethanol as a fuel in the automotive industry, fighting Henry Ford's conception.

In the 15 th century, there are mentioned the oilfields from Lucăcești (Moinești district, Bacau County (14401442) and in the 18th century those from the southern Dărmănești Depression and around Moinești. Marco Bandini related in 1646 the fact that the inhabitants of the villages of Mosoare, Poieni, Dofteana and Păcuri used as oil the oil extracted through the wells. Later, Dimitrie Cantemir in Descriptio Moldaviae remembers the existence and exploitation of oil in this region.

Oil extraction has been known in this region for over five centuries. Initially represented by primitive exploitations, then starting with the second half of the 19th century through mechanical wells and nowadays through deep wells, from $150 \mathrm{~m}$ to $1000 \mathrm{~m}$, extraction was a permanent presence in the industrial landscape of the area. The beginnings of the oil industry in Romania take place in the Trotus River basin, respectively on the Tazlăului Valley and in the Dărmănești Depression. Later, the petroleum perimeters widen much, covering larger spaces in the area of the Carpathian Paleogene.

The first drill with mechanical drilling in Romania was manufactured and used in Poieni (Târgu Ocna), Bacău in 1861 and consisted of the percussive dig with wooden poles.

The first commercial probe in the world appears in the village of Lucăcești of Moinești around the 19th century.

In Lucacesti, Bacău had already appeared the first oil distillery of an industrial character as early as 18371840 , followed by that of Moinești (1844). These are the first distilleries in the world, the first step for Romania to have the first refinery, in Ploiesti.

At the beginning of 1857, in Ploiești, the "Gas Factory" of Marin Mehedinteanu was operating, which was also the first of its kind in Romania and in the world. It was a refinery, with a primitive endowment, but which meant a big step towards civilization (Lumina, 2012).

In 1996, the Romanian Oil Company was established as a joint-stock company, established by the reorganization of RAFIROM, PECO and PETROTRANS, which were merged and ceased their activity. The Romanian Oil Company owned all ten refineries in Romania, along with the extraction fields, depots and petrol stations.

In 1997 the Romanian Oil Company was divided, 8 of the refineries operating on their own account, the rest 
of the assets coming into the ownership of the National Petroleum Company (SNP) Petrom. Thus SNP Petrom inherited two refineries (Arpechim Pitești and Petrobrazi Ploiești), the entire former PECO distribution network, the pipeline system of PETROTRANS and the exclusive right to extract crude from the oil fields in Romania.

In the year 2000, the businessman Ovidiu Tender bought from the Romanian State the company Prospecțiuni S.A, the only company in the country that provides geological prospecting for drilling.

In 2002, the company Petromservice was born through the divestment of the Petroserv branch from Petrom.

In 2004, OMV, the leading oil and gas group in Central and Eastern Europe acquired 51\% of Petrom shares from the Romanian state for a total amount of 1.53 billion Euros.

Romania currently has 10 refineries, which can be classified into two major groups: Large refineries, which concentrate about $85 \%$ of the processing capacity.

Petrobras Ploiești - its construction was started on July 17, 1934, due to the efforts of the Romanian company Credit Loan.

Arpechim Pitesti

Petroltel Ploiești - also known as the RomanianAmerican Refinery (before 1945) or Teleajen (1979-1998)

Petromidia

RAFO You were

and small refineries, totaling about $15 \%$ of the processing capacity with a lower degree of complexity

Astra Ploiești - founded in 1880 (Solomon, 2004)

Vega Ploiești - established in 1905 with an initial capacity of 0.2 million tonnes of crude oil/year

Romanian Star Campina - founded in 1895

Dărmănești Refinery

Petroleum Surplacu de Barcău

All these refineries have a total capacity of 34 million tonnes per year, well above the domestic consumption of Romania. Regarding the contract signed with Iran during the communist regime, Romania received large quantities of crude oil from this country and processed it in the Romanian refineries, because after that much of the finished products would be sold, in the Mediterranean, at dumped prices to the western countries. In exchange for Iranian oil, Romania delivered to this country tractor, cement and other products of the processing industry.

Petrobrazi and Arpechim refineries are owned by Petrom and have capacities of 7, respectively 6.5 million tonnes per year. Both have two modules, thus able to operate at half capacity. In the refining market, Petrom holds a $52 \%$ share, followed by Rompetrol with $29 \%$ and Lukoil with $17 \%$ (2007).

The Petrotel refinery was privatized in 1998 by taking over the majority stake of $51 \%$ by Lukoil, for the amount of 53.2 million USD. The new owner has upgraded the refinery, building gasoline, isomerization and hydrogen production facilities. One of the most important installations that can be found here is Coking, which results in the coke product. Petrotel is one of the few remaining refineries that can easily refine sulfur oil. The total processing volume of the refinery is 2.5 million tonnes per year.

In 1999, the privatization of the Petromidia refinery (formerly "Midia-Năvodari Petrochemical Complex") was attempted, but the Akmaya buyer did not pay his obligations, the privatization being canceled. In 2001, the refinery was sold to Rompetrol Group, which paid \$ 50 million and pledged to pay $\$ 621$ million in debt.

The processing capacity is 4.8 million tonnes per year.

The RAFO Oneesti refinery was privatized in 2001 by taking over the majority stake $(59.9 \%)$ by the consortium formed by Imperial Oil (owned by Corneliu Iacobov) and Canyon Services (Portugal) for \$ 7.48 million. The British company Balkan Petroleum took over the majority stake from this consortium in 2003. Calder-A (part of the Petrochemical Holding group) acquired Balkan Petroleum in November 2006, becoming the majority shareholder. The refinery has a capacity of 3.5 million tonnes per year.

\section{Materials and Methods}

\section{Important Findings}

The most important discovery was made in 2003 in Sighisoara, by the domestic natural gas producer Romgaz and Wintersahll AG, the largest oil and gas company in Germany.

The second discovery as important is the one made by Petrom in Torcești, near Tecuci.

A large oil field is discovered in December 2014, by excavating the exploration well Padina Nord 1 in Buzau County, at a depth of over 2,500 m (Tilică, 2014).

The most publicized failure of the exploration was that of the Anglo-Dutch Shell group in Romania. The oil giant has unsuccessfully invested $\$ 70$ million in an exploration of fields in northern Transylvania. This failure was followed a few years later, by the decision to gradually withdraw from Romania, first from the gas station market and then from the LPG market.

In the exploration sector, several companies from abroad are present in Romania, such as Sterling Resources (United Kingdom), which has a two perimeter exploration agreement in the Black Sea, Pannonian Energy (USA) and Falcon Oil (USA), in the Petrosani area, Royal in Moldova. In April 2009, ANRM said that the probable reserves in the Black Sea perimeters allocated to Sterling are 50 billion cubic meters of gas, which is the five-year gas production of Romania and 278 million oil, that is the 55-year production of Romania.

Even if new oil and gas deposits are found from time to time, this fact cannot justify the almost continuous 
operation at large capacities of many of the old processed reserves, which have long been declared on extinct. Something is going on with these old oil deposits. They are in a continually rebuild or bring other deposits from somewhere in the depths of the earth from a probably a huge and deep reserve.

In the years 1970-1980, we were alarmed that in 15-20 years the oil reserves of the country and the entire planet will be depleted so that in 2000 we will have no energy. Some were even waiting for the end of the world.

According to estimates from 2007, Romania's reserves were 74 million tonnes of crude oil, which will be exhausted in about 13 years (i.e., in 2020).

Romania's oil and natural gas reserves will be depleted in about 20 years, according to the latest measurements made by specialists at the end of 2015 (Restart energy, 2016). So four years before the exhaustion announced in 2007, we extend this term with another 20 years, which is nice and exciting.

A website that shows the international reserves calculated very carefully every day based on all the information collected daily from around the world announces that the world oil reserves consumed massively since the last century will be exhausted in about 150 years, that is somewhere between the years 2000- 2010 and today in 2020, tells us that these reserves will be exhausted exactly over another 150 years. It is then possible to give us an extension of another 150 years.

It is obvious that the existing oil reserves are restored overtime to their judicious exploitation, or they are receiving new resources from the depths of the planet.

The question that arises now is it ethical to exploit and use so much oil after about 150 years of intense exploitation of it we managed to pollute the planet that we all inhabit to a great extent?

At the first question regarding the real life of the oil and how it is produced, we will try to give an answer now, but to the second one regarding the ethics of the continued use of hydrocarbons for obtaining energy by burning them now when we can obtain nuclear power, solar, wind ... we will not try a direct answer in the present work, because the problem is an extremely difficult and disturbed, because it is much easier today to extract oil or gas even from the deep and burn them, rather than using alternative forms of energy, some of them with big problems in the constant production, having huge variations depending on the weather, that is, sometimes producing massive amounts of electricity and having periods when production is greatly diminished and needs to be replaced with energy from others resources or stored early because domestic and industrial consumption does not support a postponement.

Fossil fuels - or hydrocarbons - are chemical compounds with complex structures, usually based on the links between carbon and hydrogen atoms. The most accepted theory of the origin of hydrocarbons (so oil) is biological.

\section{How is Oil Formed?}

Under the conditions of an aquatic environment devoid of oxygen (anoxic) dead organisms - be they plants or animals - do not decompose - but enter into a slow transformation process in which the main role is played by anaerobic bacteria, those that live in the absence of oxygen.

In certain marine basins that are semi-isolated from the Planetary Ocean and where, due to the poor vertical circulation of water, oxygen shortages occur (as, for example, the Black Sea basin is present), dead organisms that fall to the bottom of the sea no longer break.

At the geological time scale, in these ponds important volumes of organic matter accumulate, which mix with the other sediments reached the bottom of the sea basin (for example clay particles carat here by the rivers on the seaside - or by the winds). At the bottom of the sea, in the oxygen-free areas, soils - or mud - called sapropelic are formed, which are very rich in organic matter (sapropelic mud has more than $10 \%$ carbon of organic origin in its composition).

An eloquent example of the marine area rich in sapropelic shore is the abyssal area of the Black Sea. Here this process of accumulation of sapropelic sludge has started in the last thousands of years and is being accumulated in the current period.

During the geological time, due to the permanent movement of the tectonic plates, the oxygen-free marine basin evolves - and the accumulation of sediments from here can lead to the cover of the sapropel banks. These layers are beginning to be buried more and more - and due to the movement of the basin where they are, they can descend to increasing depths. Under these conditions, the banks begin to turn into rocks (they solidify - and from them, the fluids begin to be expelled due to the increasing pressures). These rocks - called bituminous - because of their richness in organic matter represent the rocks from which oil results. Hydrocarbons are born at higher temperature and pressure intervals, in a well-established time window.

Due to high pressures, hydrocarbons (liquids - oil and gases - methane gas) are expelled from newly formed rocks and begin to rise to the surface. Their path to the surface is through the pores of the rocks, as well as through the cracks and cracks formed above the source layers and along the possible faults that have shaped the superficial part of the Earth.

Hydrocarbon migration can be completed in certain situations directly on the surface (when asphalt lakes are formed). In this situation the methane is lost in the atmosphere and the oil is oxidized - that is, it decomposes under the action of oxygen. In other 
situations, however, this migration phenomenon can end by accumulating hydrocarbons in the deposits.

It is necessary to fulfill several conditions simultaneously, without which the hydrocarbons expelled from the bituminous layers cannot be stored.

\section{The Existence of a Rock-Reservoir}

Hydrocarbons accumulate and then can be found in permeable and/or cracked permeable rocks, usually sandstone (old sands cemented in time, oil existing in pores between particles), limestone or dolomite cracked.

\section{Existence of an Impermeable Roof of the Reservoir Rock}

In order for the hydrocarbons not to migrate further to the surface, the reservoir rock must be protected at its top by another rock, impervious, such as clay.

\section{The Existence of a "Trap"}

The reservoir rocks in which we can find hydrocarbons were usually without communication (waterproofed) by the adjacent layers, which blocked the migration of hydrocarbons on the sides. These traps are often - structures formed due to the movements of the Earth. The most classic are structures called anticlinal, which have bell or dome shape. The hydrocarbons thus accumulate at the top of the dome (bell) and, if the reservoir rock is not affected by tectonic movements that disassociate it, they can remain here for a long time. These structures are hydrocarbon deposits which, if they have significant volumes of oil and/or gas, are considered deposits (Stanica, 2009).

Several years ago we were taught at school that oil was formed from the decomposition of large organisms such as dead dinosaurs, but today when it has been observed that the deposits are restored over time and dinosaurs no longer exist for millions of years, they stopped giving up this theory and passed exclusively on marine microorganisms that deposit massively at the bottom of the water, decompose in time and then form oil. This somewhat more palpable theory does not explain the continuous restoration of rationally exploited oil deposits and especially of those today are no longer under the seas or oceans.

In the last decade's oil workers have noticed a strange phenomenon, all over the world: The oil wells that were considered exhausted due to the exploitation began to be filled again with "black gold".

There are two theories about the origin of oil. The first is the organic, or biogenic one, which belongs to the Russian scientist Michael Lomonosov. He said that this fuel appeared through the decomposition, under certain conditions, of biological waste over millions of years. Unlike Lomonosov, another enlightened mind, the chemist Dmitri Mendeleev, the author of the periodic table of elements, believed that oil represents not a substance formed by the decay of plants and animals that once lived on Earth, but a primordial material, born on the outskirts of the planet, which constantly erupts towards its surface, like the magma of volcanoes.

In the case of Grozny, the capital of Chechnya, things seem even stranger. Oil exploitation began here in 1897 . Until 1960, when the deposit was considered depleted, no less than 100 million tons of crude oil was extracted. To the surprise of geologists, in recent years oil has actually started to sprout from the earth and locals gather it with buckets. The situation was repeated in the case of the Eugene Island oil basin off the coast of Louisiana, USA. Reserves here have been considered depleted, but over the past decade, several surveys have shown that they have been restored, with extraction reaching levels comparable to those of previous decades (Coja, 2012).

A 1999 article in the Wall Street Journal shows that most geologists are very pressured to explain why the world's largest oil reservoir, the Middle East, has exceeded double reserves in the last 20 years, despite intense exploits and relatively few new discoveries. Many dinosaurs and prehistoric plants would be needed to explain the estimated 660 billion barrels of oil in the region, notes Norman Hyne, a professor at the University of Tulsa.

Perhaps the most intriguing article is that "scientists who study oil fields say that the oil coming out now has a geological age different from that of 10 years ago," and this disparity is explained by the Wall Street Journal. Thomas Gold, emeritus professor at Cornell University: "Oil is, in fact, renewable, a primordial syrup made continuously by the Earth under conditions of extreme pressure and temperature. As it migrates to the surface it is attacked by bacteria, which makes it appear to have an organic origin, dating back to the time of the dinosaurs" (Coja, 2012).

A study published in Science Magazine on February 1, 2008, presents new evidence supporting the abiotic theory of oil. (..) Proskurowski found hydrocarbons containing isotope 13 of carbon that seems to be formed in the earth's mantle rather than biological matter from the bottom of the ocean. Isotope 13 is the type of carbon associated with scientists with the abiotic origin, as compared to isotope 12, which scientists usually associate with biological origin. The discovery of abiotic hydrocarbons in the Lost City marine area is the second discovery in recent years that provides arguments for the abiotic origin of oil.

As presented by WorldNetDaily in 2005, a NASA probe sent on Titan (Saturn's gigantic moon) discovered methane with carbon-13 isotopes, which the agency said were abiotic in origin. WorldNetDaily says that developing deep-water drilling for natural gas extraction poses serious problems for fossil fuel theory. The GHK 
company in Oklahoma found natural gas in two wells dug at a depth of about 5.7 miles, far too deep for dinosaur remains to be present.

Following their abiotic theory, Russian and Ukrainian geophysicists and chemists have begun detailed analyzes of the tectonic history and geological structure of the crystalline layers in the Dnieper-Donets basin. Then came the geophysical and geochemical investigations.

A total of 61 boreholes were dug and 37 became commercially productive. And this is an extremely impressive performance, a success rate of about $60 \%$. The size of the discovered deposit was comparable to that of northern Alaska. In the USA, a 10\% success rate was considered a performance at that time !!! So 9 out of ten boreholes were just "dry holes".

By the 1960s, while American oil companies were taking control of areas in Saudi Arabia, Kuwait, Iran and other areas of cheap oil, the Soviets were concerned about testing their alternative theory. They started digging wells in supposedly sterile regions of Siberia. There they developed 11 major ponds plus a giant one, all based on their abiotic theory.

In the 1980s they went to Vietnam and offered to finance drilling costs and to show that their new theory works. The Russian company Petrosov drilled in the outer area of Vietnam's White Tiger basin, using the basalt rock and made it possible to extract 6,000 barrels per day for the weak Vietnamese economy.

In the USSR, geologists trained in abiotic theory perfected their technology and, in the mid-1980s, the USSR emerged as the largest oil producer in the world. Few in the West understood what was happening or bothered to ask (Kenney, 2020).
A map made available by the CIA in 2009 (Fig. 1) is only valid today partially because the deposits have since been restored, many others have appeared, so it can only be useful for presenting the locations of the basic extraction, but the figures with the available reserves are no longer relevant.

Natural gas is a flammable gas that is in the form of a deposit in the deep layers of the earth. Natural gas is associated with oil deposits, their formation processes being similar. The composition of natural gas consists mostly of methane and is distinguished by the chemical composition.

Natural gas is a mixture of gases, which can be very different after settling the deposit. Most are made up of methane, to which are sometimes added appreciable amounts of saturated hydrocarbons (alkanes), methane $\left(\mathrm{CH}_{4}\right)$, ethane $\left(\mathrm{C}_{2} \mathrm{H}_{6}\right)$, propane $\left(\mathrm{C}_{3} \mathrm{H}_{8}\right)$, unsaturated hydrocarbons, alkenes or olefins and aromatic or aromatic hydrocarbons which is the chemical formula chain have a double bond (=) as ethene (ethylene) $\mathrm{C}_{2} \mathrm{H}_{4}$. Alkanes having a ring chemical structure are also called cycloalkanes, having the general chemical formula $\mathrm{CnH} 2 \mathrm{n}$. Alkenes can also have cyclic forms such as cyclopentane.

Alkynes are hydrocarbons containing several triple chemical bonds, the most representative being ethine (acetylene): $\mathrm{C}_{2} \mathrm{H}_{2}$. The last most important group of unsaturated hydrocarbons is benzene which has a cyclic structural form: $\mathrm{C}_{6} \mathrm{H}_{6}$; Naphthalene: $\mathrm{C}_{10} \mathrm{H}_{8}$ is part of a subgroup of these aromatic hydrocarbons, while terpenes (turpentine) are not chemically pure hydrocarbons.

Natural gas also contains condensate gas vapors of which are also called humid gases, hydrogen sulfide $\left(\mathrm{H}_{2} \mathrm{~S}\right)$, which requires the removal of sulfur and up to $9 \%$ carbon dioxide $\left(\mathrm{CO}_{2}\right)$ which diminishes the quality of the gas.

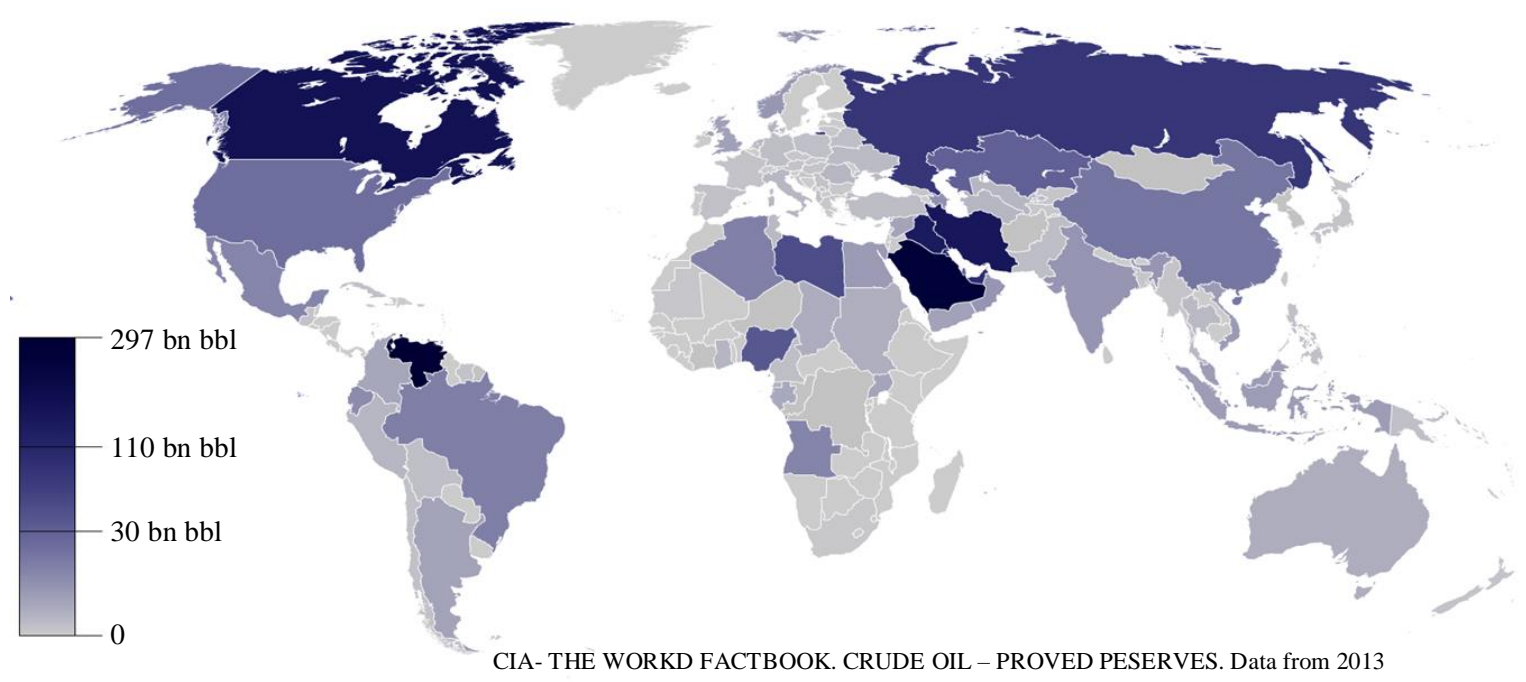

Fig. 1: Map of the 2009 world oil reserves 
In general, natural gas comprises $85 \%$ methane, $4 \%$ other alkanes (ethane, propane, butane, pentane) and $11 \%$ inert gas (which does not burn). Particularly valuable are natural gases containing helium, these gases being the main source of helium.

15 states operate $84 \%$ of global gas production (Fig. 2).

Natural gas is born through processes similar to the oil that is commonly found. The old theory says that gas is formed from dead microscopic organisms (algae, plankton) being isolated from atmospheric air, in the presence of high temperatures and pressures, conditions that were born by sedimentation at the bottom of the seas being subsequently covered by impervious layers of earth.

Most of the natural gas formed 15 to 600 million years ago, being associated with oil fields, can rarely find the unique oil or gas fields. For the first time in 1844 natural gas was found in the area of the eastern station of Vienna in Europe, followed by new discoveries in 1892 through drilling in the Wels region, Austria. Large gas fields are found in North Field (over 900 TCF or 25 billion $\left(10^{12}\right)$ $\mathrm{m}^{3}$ ) in Qatar (Arabian peninsula) and Urengoi (over 300 TCF or 8 billion $\left(10^{12}\right) \mathrm{m}^{3}$ ) in Siberia, Russia. It also assumes the existence of larger gas deposits in Iran.

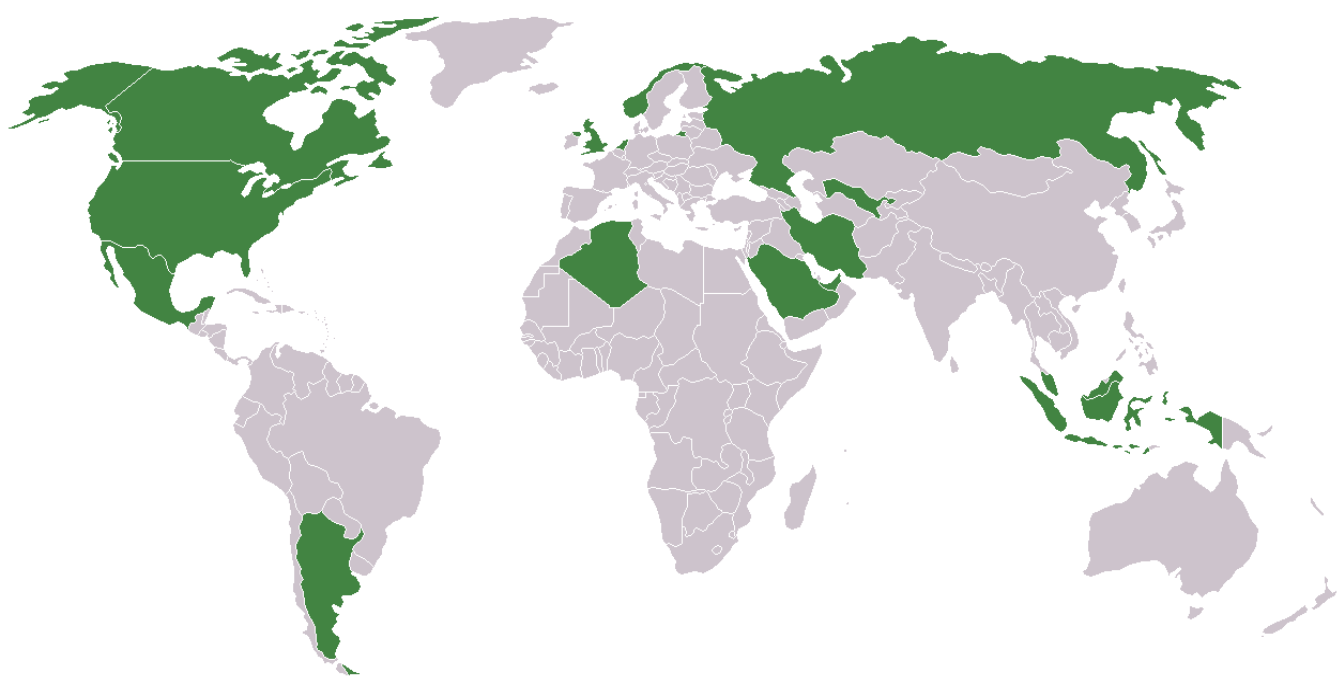

Fig. 2: 15 states operate $84 \%$ of global gas production

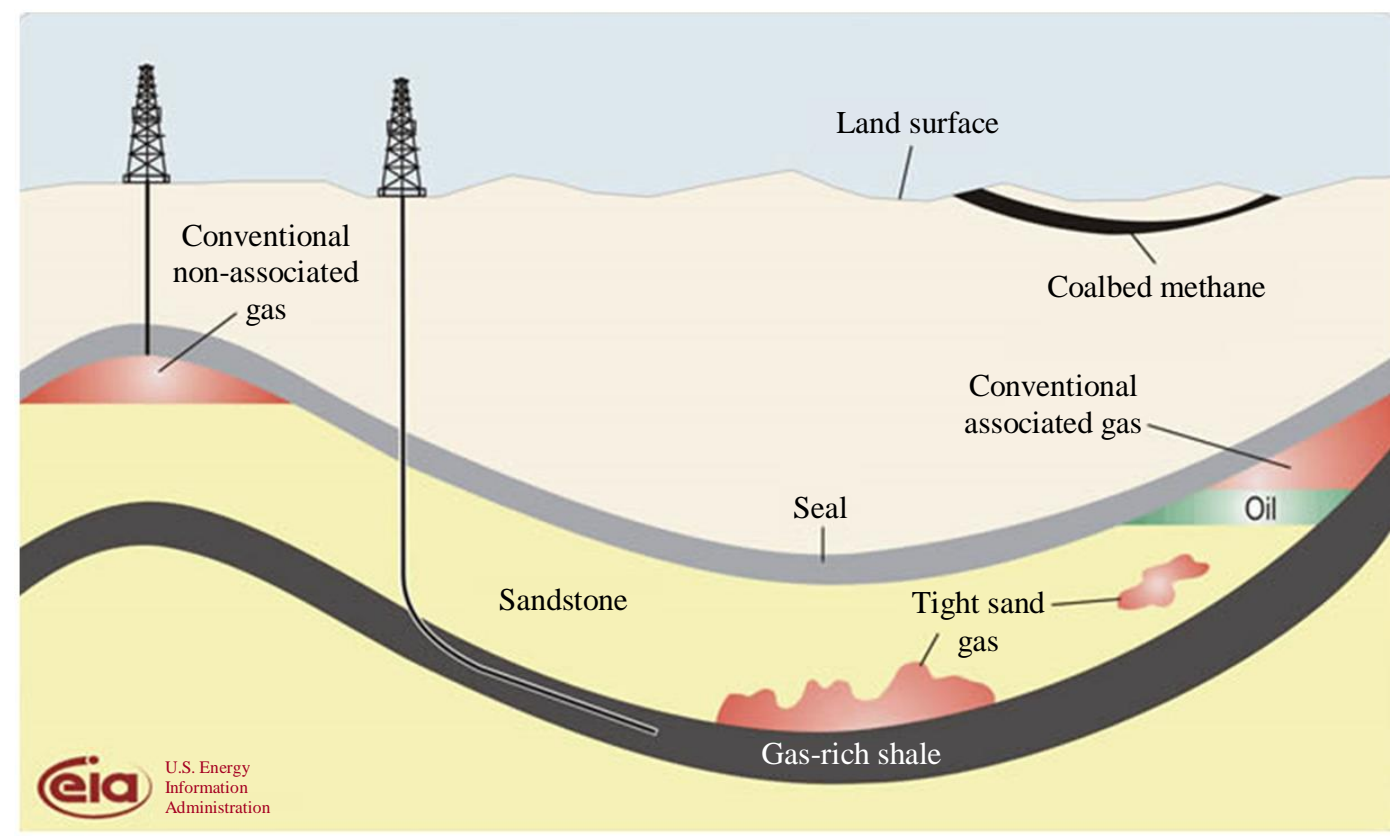

Fig. 3: Schematic cross-section of the subsurface illustrating types of natural deep gas deposits 


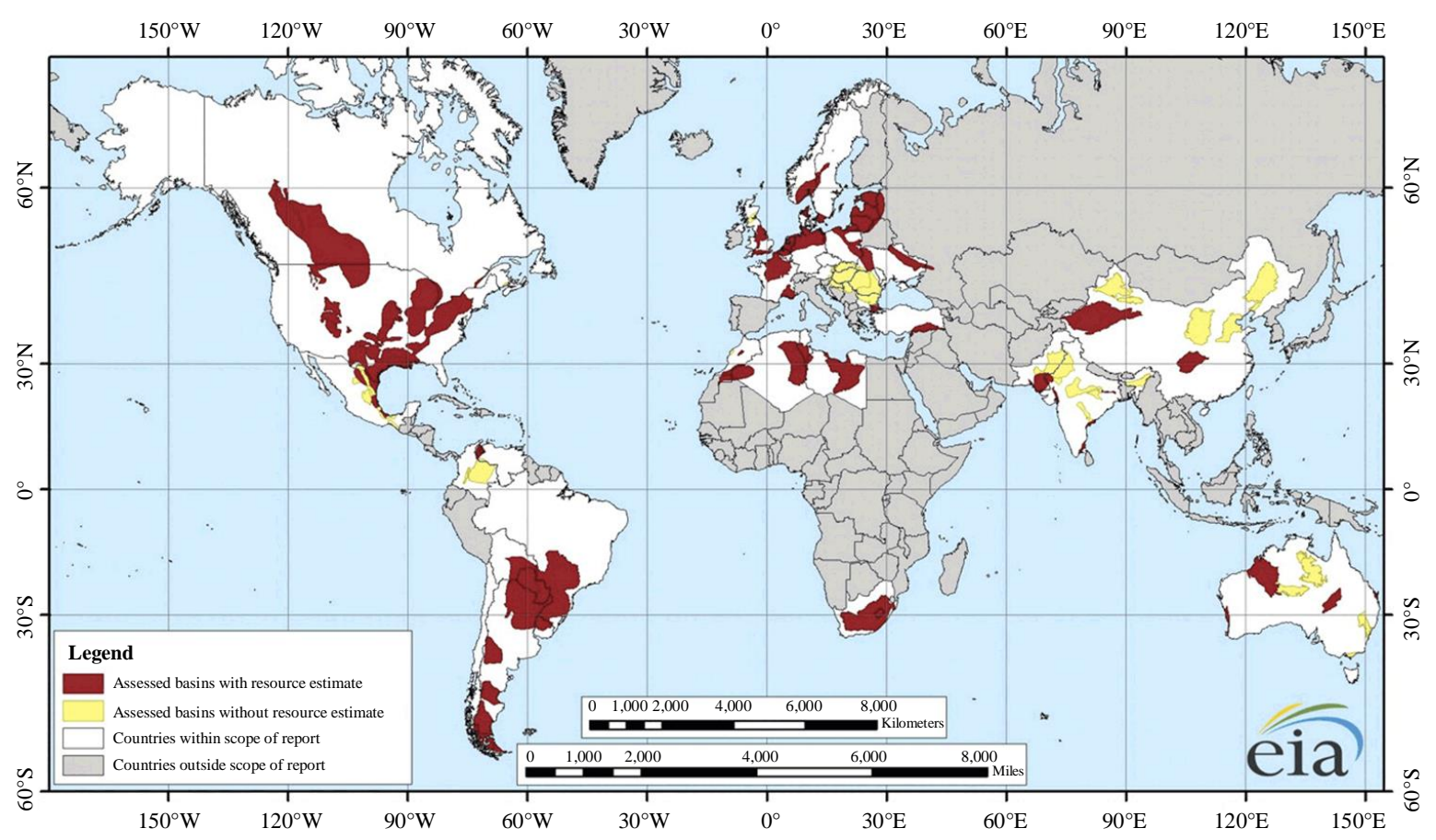

Fig. 4: Propagation of shale gas deposits

Shale gas is an improper name of a source of gas originated by applying a mechanical release process on the host rock (the rock containing the gas). The improper name comes from the fact that in the Romanian literature no equivalence (at the vocabulary level) has been established between the rocks derived by the incremental metamorphic action on sediments rich in clay minerals. To align the terminology to international literature and nomenclature we will refer to this type of gas as shale gas. Schematic cross-section of the subsurface illustrating types of natural deep gas deposits can be seen in the Fig. 3.

The equivalent of the metamorphic rock containing the gas is shale (English lb.) from which the name of shale oil also comes. The level of metamorphism (expressed in terms of temperature and pressure) reached in the shale rocks determines the migration of gas (whatever its nature) and implicitly does not favor the accumulation of gas in this type of rocks.

The exploitation of this type of deposit requires a more complex technology than the one involved in the exploitation of conventional gases and has as its characteristic the oblique and horizontal drilling over long distances. For this reason, this type of deposit together with the technology involved for its exploitation is also called unconventional. The drilling techniques were initially developed and applied in the United States, where there are already over 50 thousand shallow wells.

The success obtained determined the application of the technique in other areas where this type of deposit is present. Already Canada has identified shale gases from similar deposits in Appalachia and British Columbia. In Europe, Poland holds the largest shale gas deposits, estimated at 5,300 billion cubic meters. In Ukraine, shale gas reserves amount to at least 30 trillion cubic meters (Fig. 4).

\section{Results}

The cosmic space also called outer space is the whole space beyond the limit of the atmosphere of a planet. The cosmic space is, in a first approximation, empty. However, it is not completely devoid of content but is filled with extremely low-pressure gases and powders. The cosmic space contains gravitational fields, electromagnetic radiation, neutrinos. Theoretically, it also contains black energy and dark matter. Because the atmosphere does not end abruptly but becomes progressively thinner, there is no clearly defined boundary between the atmosphere and the cosmic space.

Virtually all planets contain gases of different types, all being hydrocarbons similar to those on earth, which clearly indicates the extraterrestrial origin of gases and of course the oil often associated with natural gas. From the study of the motion of galaxies, it was discovered that the universe contains much more matter than is represented by visible objects: Stars, galaxies, nebulae and interstellar gas. Some of the most spectacular astronomical photographs show interstellar gas located near hot stars (Fig. 5). The strongest line in the visible region of the hydrogen spectrum is the red line in the (Between the Stars: Gas and Dust in Space). Scientists 
also call this red Balmer line the $\mathrm{H}$-alpha line, with alpha meaning it is the first spectral line in the Balmer series. (as explained in the chapter on Radiation and Spectra); this emission line accounts for the characteristic red glow in images like Fig. 5.

There are planets made up of a large amount of gas and the vast majority of planets have gas in their atmosphere. Hydrogen and carbon are the most common elements in the universe and their combination in the form of gas is found everywhere in the universe and obviously also in our solar system and in these conditions to claim that they were born from dead animals gathered at a place and then in decay, including dinosaurs is equivalent to saying that the entire universe and our solar system were once populated with animals and especially with dinosaurs that flew and flew all over the galaxies so that at one point they would bury themselves and all go into decay to fill the universe with gas.

Greater stupidity would not be possible than to sustain the origin of gases from dinosaurs or rotten animals when the entire universe abounds in gases, which flow on planets from within them and some planets also have an atmosphere composed of gases and even there are formed planets only from gases as a whole, instead of from the earth, which indicates the gaseous origin of many planets. It should also be mentioned that these abundant gases in the universe have their origin and age.

Considering the fact that our entire universe abounds in hydrogen gas and has and a lot of carbon, it is easy to assume that the combination of the two elements gave birth to hydrocarbons.

Titan (or Saturn VI) is the largest satellite on the planet Saturn. This is the only known natural satellite that has a dense atmosphere and the only celestial body, other than Earth, for which there is clear evidence that it has a liquid surface.

Titan is the sixth spheroidal satellite of the planet Saturn. Often described as a planet-satellite, Titan is about $50 \%$ larger in diameter than the Moon, Earth's satellite and is $80 \%$ more massive. This is the secondlargest satellite in the Solar System, after Ganymede, Jupiter's satellite and is larger in volume than the smallest planet in the Solar System, Mercury, though only half as a mass. The gravitational acceleration from the surface $(0.14 \mathrm{~g})$ is slightly lower than the monthly acceleration $(0.17 \mathrm{~g})$. Titan was Saturn's first known satellite, discovered in 1655 by Dutch astronomer Christiaan Huygens and was the fifth satellite of a planet outside of Earth that was discovered by humans.

Titan is made up mainly of ice water and rock. As with the planet Venus before the space age, the dense and opaque atmosphere prevented the study of the surface of Titan. Currently, there is sufficient information about the surface of the satellite with the arrival of the Cassini-Huygens mission in 2004, which has also discovered liquid hydrocarbon lakes in the polar regions of the satellite (Nasa Portal. News Features: The Story of Saturn).

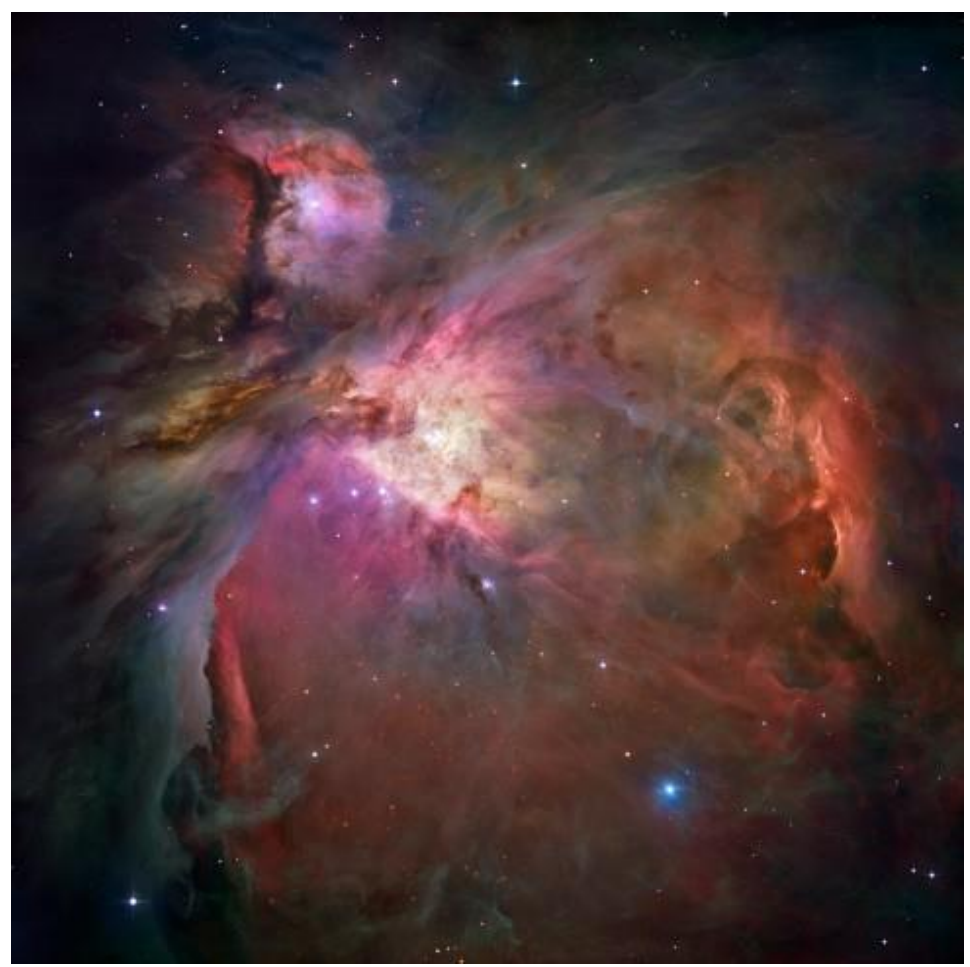

Fig. 5: Between the Stars: Gas and Dust in Space 
Hydrogen, the element whose nuclear fusion gives life to stars, including the Sun, is an extremely important wheel in the gear of the Universe and is also the most widespread element in the Universe, being the simplest of all chemical elements.

The Big Bang generated the germs of all the chemical elements in the Periodic Table, the constituent elements of the Universe. Each element has a unique number of subatomic particles: Protons (positively charged particles), neutrons (neutrals) and electrons (negatively charged). Hydrogen consists of a proton and an electron (it is the only known chemical element that has no neutrons) and is the simplest element in the universe, which explains its abundance.

Large agglomerations of hydrogen atoms in cosmic clouds can, under certain circumstances of pressure and temperature, cause the stars to ignite. The hydrogen in the stars fuses to form helium - the second most widespread element in the universe - according to Encyclopedia.com. Helium has two protons, two neutrons and two electrons. Together, hydrogen and helium represent no less than 99.9\% of known matter in the Universe. Even so, hydrogen is about 10 times more abundant than helium. Oxygen, which ranks third in abundance in the universe, is almost 1,000 times rarer than hydrogen.

In general, the higher the atomic number of an element, the rarer it is.

Compared to the composition and abundance of elements in the Universe, the Earth is an exception. Oxygen, not hydrogen, is the most abundant by weight in the earth's crust, followed by silicon, aluminum and iron. Oxygen also predominates in the human body, followed by carbon and hydrogen.

Hydrogen is also extremely important for the human body. Hydrogen bonds give DNA molecules the characteristic double helix shape and this element plays a key role in maintaining an optimal $\mathrm{pH}$ level (acidity level) in the body.

If the inside of the stomach (for example) becomes too basic an environment, hydrogen is released from the chemical compounds in which it is included, increasing the level of acidity. If it is too acidic, the hydrogen will bind to other elements.

Another extremely important function of hydrogen allows ice to float on water $\left(\mathrm{H}_{2} \mathrm{O}\right)$ - hydrogen bonds push frozen water molecules in opposite directions, lowering their density. "Usually substances are denser in the solidstate than in the liquid state. Water is the only substance that is less dense when it is in the solid-state."

Hydrogen can also be extremely dangerous. The interaction between hydrogen gas and oxygen led, for example, to the fire that destroyed the Hindenburg airship, an accident in 1937 that killed 36 people. Moreover, hydrogen bombs have incredibly high destructive potential. Like atomic bombs, hydrogen bombs cause destruction using a combination of fusion and nuclear fission reactions.

"The important difference between the hydrogen bomb and the atomic ones, which were dropped on Japan at the end of World War II, is that the hydrogen bomb does not generate radioactive contamination (...) The danger of hydrogen bombs is strictly related to the force shock wave mechanics and not radioactivity, "but the power of a hydrogen bomb can be 1,000 times greater than the first two atomic bombs.

It sometimes happens that accumulations of gases in the universe ignite and cause large fires or even strong explosions somewhere in distant space.

In the Universe, hydrogen is found mainly in the form of an atom and in a plasma state. Their properties are different from those of the hydrogen molecule. The electron and the hydrogen proton do not form bonds in the plasma state, due to different electrical conductivity and high radiative emission (the origin of light emitted by the Sun and other stars). Particles charged with electric charges are strongly influenced by magnetic and electric fields. For example, in solar winds the particles interact with the Earth's magnetosphere, generating Birkeland currents and producing the phenomenon known as the northern lights. Hydrogen is found in a neutral atomic state in the interstellar medium and the largest amount is found in Lyman-alpha systems (Storrie-Lombardi, 2000).

Under normal conditions, hydrogen remained in the form of diatomic molecules, $\mathrm{H}_{2}$, it is not very widespread in the Earth's atmosphere (at an average concentration of 1 ppm by volume) due to its small mass, so its gravitational effect of the planet is actually very weak. However, hydrogen (through its compounds) is the most widespread element of the earth's zone. Its most common and chemical compounds are hydrocarbons and water. Hydrogen gas is the product of specific species of bacteria and algae, which are the main components of flatulence. Methane is an important source of hydrogen (Berger, 2007).

It is therefore shown that in our earth, where hydrogen has combined in enormous quantities with oxygen resulting in water, it is also combined as in the whole universe with carbon or carbon and oxygen, resulting in various forms of hydrocarbon molecular chains, various hydrocarbons, a very widespread fuel on Earth as in our entire universe, since its formation. These very energetic combinations of hydrocarbon gases on earth are often found hidden in the depths of the earth's crust, or even very deep inside the earth, towards its middle, from where they come to the surface through certain channels dug during by the planet's internal pressure, feeding those known bags of oil and/or gas permanently with the gases from the largest interior on the planet (Berger, 2007). 
As long as a reserve (bag) of oil or gas is not emptied very quickly, but is rationally exploited, it will recover normally by feeding from the internal source of the planet.

In addition to carbon dioxide, increasing methane concentrations is a major concern. The relative growth rate of methane has far exceeded that of carbon dioxide in recent decades. Molecule by molecule, this gas is much stronger as a greenhouse gas than carbon dioxide, although it is much shorter in the atmosphere. Methane now provides about 20 percent of the greenhouse effect, so the future development of its abundance in the atmosphere is of great interest. The current growth rate (from 1 to 1.5 percent per year) is equivalent to adding 30 to 40 percent of $\mathrm{CO}_{2}$ to the current intake, in terms of radiative effect.

Methane is partly the result of the growth of food and animals (rice, cattle), the production of landfills (decomposition of organic matter) and deforestation (burning and degradation of wood), as well as a byproduct of the hydrocarbon economy. None of these sources are expected to decline in the future. On the contrary, with more than 100 million people in need of food and fuel each year, the expectation must be for increased methane release from human activities.

Another source of methane is a natural release from a variety of processes, such as the decomposition of wet peat and the degradation of organic matter in stagnant ponds and heating at sea. For these sources, changes in the environment caused by global warming are important. For example, thawing of permafrost in Alaska and Siberia can significantly affect the methane budget, as organic matter that previously could not be affected, can decompose, after thawing, in a humid environment with a lack of free oxygen. This is a recipe for methane production. We do not know how long global warming will last (depending on the future release of greenhouse gases and all associated climate physics) and we do not know the effect of such warming on potential methane sources. Therefore, all estimates of future methane emissions from natural sources are pure beliefs.

Some ideas about how methane changes in the atmosphere in response to global warming and cooling can be derived from studies of climate history. The long core of ice drilled at the Vostok station in Antarctica provides a record of atmospheric gas concentrations and climate over the past 400,000 years. The ancient concentration of methane and carbon dioxide is stored in air bubbles trapped in ice. In addition, previous temperature estimates can be obtained from the hydrogen and oxygen isotope ratios of ice molecules. Methane concentrations have varied considerably throughout Earth's recent history. The correlation between $\mathrm{CH}_{4}$ records and Antarctic temperature records is remarkable. It supports the idea that methane has amplified climate change (i.e., provided positive feedback). The major transitions from the lowest to the highest methane values are associated with each temperature transition from cold climate (ice ages or glacial conditions) to warm (interglacial) climates. At these times, called (terminations), atmospheric concentrations of $\mathrm{CH}_{4}$ increased from 320-350 p.p.v.v to 650-770 p.p.b.v (parts per billion in volume). Why did $\mathrm{CH}_{4}$ grow so fast during these terminations? This is one of the great unknowns in climate research. Melted permafrost, swamps grow at low latitudes as sea levels rise and a general rise in wetlands on the continents is likely candidates. It is also possible that a warming ocean triggered the release of methane from the coast due to the melting of methane hydrates (Berger, 2007).

\section{Discussion}

The international meter shows the capacity of the oil and gas bags at a certain moment, so it is an erroneous measurement because it does not take into account their refueling from inside the planet in time. Thus in the 1980s it shows the disappearance of hydrocarbons in about 20-30 years and after 40 years in 2020 it indicates a reserve until exhaustion of about 160 years, so that after 160 years of terrestrial exploitation of hydrocarbons they have recovered today for another 160 years and obviously will continue to recover.

The real problem is not an economic one, that new oil reserves are being sold at low prices, although it is known that they will recover over time, but it is an ethical one.

Can we still accept this situation?

Oil lovers and big oil companies say we continue to accept their enormous pollution by burning them, because they will soon be depleted and in addition, fossil fuel prices will continue to rise based on the same threat, while their opponents do not big changes in the energy equation of the planet considering that maybe it's more convenient to wait first for the depletion of hydrocarbon resources, an exhaustion that no longer comes.

In this way, we all managed after generations to pollute the planet we all live on, the only one we have available today, at a maximum level in just 160 years of super-exploitation of hydrocarbons.

If we continue in the same way, we will no longer be able to live on this planet, which has turned brown from blue and even shades of gray and which makes it all the harder life for us.

If in just 160 years we have destroyed all ecosystems of the planet, to the limit, can we still afford another 160 years in the same way? Will the planet last? She's already showing us no!

In 160 years, the generations of that time, much more tired than us, on an almost exhausted planet, will they be able to do something for it? Isn't it too late then?

Today we all talk, we search for solutions, but practically not much is being done for radical changes that are already obviously necessary until it is too late. 
This paper wants to raise awareness not only of public opinion but also of the current experts and scientists, inhabitants of the planet earth (still partially blue planet) so that we can all try to take some radical measures so that our lives here can improve quickly and to leave a good place and to our descendants.

\section{Conclusion}

Hydrogen, the element whose nuclear fusion gives life to stars, including the Sun, is an extremely important wheel in the gear of the Universe and is also the most widespread element in the Universe, being the simplest of all chemical elements.

The universe we live in is designed in such a way that it abounds in hydrogen, carbon, or combined gases, i.e., hydrocarbons, which under certain conditions pass into a viscous liquid state thus producing oil in large quantities. It is ridiculous to much longer support the theory that gases inside the earth were formed like oil otherwise from organic matter decomposed over time, possibly from dead dinosaurs that rotted and then turned into oil and gas.

The planet's gas and oil energy resources have to be managed differently than before, given that they are permanently restored.

Today we can no longer consider the theory of formation of oil and natural gas from dead and fossilized dinosaurs, because we have learned the truth, namely that the entire universe in which we live is composed of gases and hydrocarbons, as well as our solar system, these being present inside the planets, on their surface, or even in their atmosphere.

The current natural gas reserves need to be reconsidered because the discovered bags are actually doors to the deeps or natural gas galleries that are constantly refreshed from the deep gas reserves. For this reason, we have the obligation to reconsider the energy value of a reserve that represents, in reality, a gateway to the massive reserves inside the planet and not just a consumable bag. As long as a reserve (bag) of oil or gas is not emptied very quickly, but is rationally exploited, it will recover normally by feeding from the internal source of the planet.

This paper wants to raise awareness not only of public opinion but also of the current experts and scientists, inhabitants of the planet earth (still partially blue planet) so that we can all try to take some radical measures so that our lives here can improve quickly and to leave a good place and to our descendants.

\section{Acknowledgment}

The author acknowledges INIS for his research in the field.

\section{Ethics}

This article is original and contains unpublished material. Author declares that are not ethical issues and no conflict of interest that may arise after the publication of this manuscript.

\section{References}

Bălan, Ș. And N.Ș. Mihăilescu, 1985. History of Science and Technology in Romania, Chronological Data. 1st Edn., Publishing House of the Academy of the Socialist Republic of Romania, Bucharest, pp: 21.

Berger, W.H., 2007. The future of methane. University of California, San Diego.

Between the Stars: Gas and Dust in Space. https://courses.lumenlearning.com/astronomy/chapte r/interstellar-gas/\#footnote1

Boncu, C.M., 1971. Contributions to the History of Romanian Oil. 1st Edn., Publishing House of the Academy of the Socialist Republic of Romania.

Lumina, Z., 2012. Bucharest, the first city illuminated with lamp oil.

Coja, I., 2012, The depleted crude oil fields are being restored by themselves.

Eakins, T., 2002. The world's first oil refinery opens in Ploiesti, Romania. WORLD EVENTS.

Kenney, J.F., 2020. An introduction to the modern petroleum science and to the Russian-Ukrainian theory of deep, abiotic petroleum origins. Russian Academy of Sciences - Joint Institute of the Physics of the Earth. Gas Resources Corporation, 11811 North Freeway, Houston, TX 77060, U.S.A.

Nasa Portal. News Features: The story of Saturn. Cassini - Huygens mission to Saturn and titan. NASA and JPL. http://web.archive.org/web/20051202030828/http://s aturn.jpl.nasa.gov/news/features/saturnstory/moons.cfm

Petrescu, F.I.T., 2014. Nuclear fusion. Infinite Energy, 20: 44-47.

Petrescu, F.I.T., 2012a. Cold Nuclear Fusion. 1st Edn., BoD - Books on Demand, ISBN-10: 3848228521, pp: 102.

Petrescu, F.I.T., 2012b. Cold Nuclear Fusion. 1st Edn., Create Space Publisher, USA, ISBN-13: 978-1- 4782-3426-5, pp: 80.

Petrescu, F.I.T., 2012c. A New Atomic Model. 1st Edn., Books On Demand, ISBN-13: 978-3848218943, pp: 62 .

Petrescu, R.V., R. Aversa, S. Li, R. Bucinell and S. Kosaitis et al., 2017a. Electron dimensions. Am. J. Eng. Applied Sci., 10: 584-602. DOI: 10.3844/ajeassp.2017.584.602 
Petrescu, R.V., R. Aversa, S. Kozaitis, A. Apicella and F.I.T. Petrescu, 2017b. Deuteron dimensions. Am. J. Eng. Applied Sci., 10: 649-654.

DOI: 10.3844/ajeassp.2017.649.654

Petrescu, R.V., R. Aversa, S. Kozaitis, A. Apicella and F.I.T. Petrescu, 2017c. Some proposed solutions to achieve nuclear fusion. Am. J. Eng. Applied Sci., 10: 703-708. DOI: 10.3844/ajeassp.2017.703.708

Petrescu, R.V., R. Aversa, S. Kozaitis, A. Apicella and F.I.T. Petrescu, 2017d. Some basic reactions in nuclear fusion. Am. J. Eng. Applied Sci., 10: 709-716. DOI: 10.3844/ajeassp.2017.709.716

Petrescu, F.I.T., 2019. About the nuclear particles' structure and dimensions. Comp. Part. Mech., 6: 191-194. DOI: 10.1007/s40571-018-0206-7

Petrescu, F.I.T., 2018. About the triton structure. Am. J. Eng. Applied Sci., 11: 1293-1297. DOI: 10.3844/ajeassp.2018.1293.1297

Petrescu, N. and F. Petrescu, 2018. Elementary structure of matter can be studied with new quantum computers. Am. J. Eng. Applied Sci., 11: 1062-1075. DOI: 10.3844/ajeassp.2018.1062.1075

Petrescu, F.I.T. and R.V.V., Petrescu, 2019. Nuclear hydrogen structure and dimensions. Int. J. Hydrogen Energy, 44: 10833-10837.

DOI: 10.1016/j.ijhydene.2019.02.140

Restart Energy, 2016. Romania's oil and natural gas reserves will be exhausted in about 20 years.
Stanica, A., 2009. The hydrocarbon deposits are formed.

Solomon, L., 2004. After closing, the Astra Refinery will go into bankruptcy. The Guardian.

Storrie-Lombardi, L.J., 2000. Surveys for z > 3 damped Lyman-alpha absorption systems: The evolution of neutral gas. Astrophys. J., 543: 552-576.

Tilică, O., 2014. Oil discovery in Buzău county; possibly the largest deposit in the last 30 years in Muntenia.

\section{Figures Sources}

Fig. 1: https://ro.wikipedia.org/wiki/Petrol\#/media/Fi\%C8\%99i er:Oil_Reserves.png

Fig. 2:

https://ro.wikipedia.org/wiki/Gaz_natural\#/media/Fi \%C8\%99ier:KarteErdgasWeltproduktion.png

Fig. 3: https://upload.wikimedia.org/wikipedia/commons/b/bb/ GasDepositDiagram.jpg

Fig.

https://ro.wikipedia.org/wiki/Gaz_de_\%C8\%99ist\#/medi a/Fi\%C8\%99ier:EIA_World_Shale_Gas_Map.png

Fig. 5: https://s3-us-west-2.amazonaws.com/coursesimages/wp-

content/uploads/sites/1095/2016/11/03160512/OSC_Astr o_20_02_Nebula.jpg 